\title{
ETS-1 Induces Endothelial-Like Differentiation and Promotes Metastasis in Non-Small Cell Lung Cancer
}

\author{
Xiaoshu Zhou Rui Zhou $^{\mathrm{a}}$ Hongxia Zhou $^{\mathrm{a}}$ Qianwen Lia Jiaxin Hong ${ }^{\mathrm{a}}$ \\ Rui Menga Fang Zhu ${ }^{a}$ Sheng Zhang ${ }^{a}$ Xiaofang Daia Gang Penga \\ Gang Wu ${ }^{a}$ Zhenyu Li ${ }^{a}$ \\ aCancer Center, Union Hospital, Tongji Medical College, Huazhong University of Science and \\ Technology, Wuhan, China
}

\section{Key Words}

ETS-1 • Endothelial-like cells • Metastasis • NSCLC

\begin{abstract}
Background/Aims: Recently, endothelial-like cells originating directly from tumor cells have been revealed. However, the mechanism remains unclear. ETS-1 (E26 transformation specific-1), a key transcription factor in the generation and maturation of ECs (endothelial cells), has been reported to be overexpressed in several cancers. Here, we reveal novel regulation of the endothelial-like differentiation of NSCLC (non-small cell lung cancer) cells by ETS- 1 . Methods: We up-regulated the expression of ETS-1 in NSCLC cell lines by $\mathrm{H}_{2} \mathrm{O}_{2}$ or lentiviral vector. Endothelial phenotypes, such as VWF (von Willebrand factor) and VE-cadherin were examined by Western blot analysis and immunofluorescence assay. Tube formation assay and phagocytotic activity assay were performed to evaluate ECs' specific features on NSCLC cells. The effect of ETS-1 on metastasis was determined by wound healing assays, transwell assays and a xenograft tumor model. To explore the role of ETS-1 in the initiation and progression of NSCLC, we examined ETS-1 levels in NSCLC cancerous tissues and paired adjacent normal tissues by immunohistochemstry and analyzed the relationship between ETS-1 levels and clinicopathological parameters, as well as patient survival. Kaplan Meier plotter database was used to assess the prognostic value of ETS-1 in NSCLC. The association between ETS-1 levels and MVD (microvessel density) was analyzed to determine their role in angiogenesis. Results: With ETS-1 up-regulation, the expression of VWF and VE-cadherin was increased in NSCLC cells. Additionally, cells adopted several ECs' specific features, including enhanced tube formation ability and uptake of Dil-ac-LDL (acetylated low-density lipoprotein) and lectin. ETS-1 up-regulation also promoted cell migration, invasion and adhesion. In addition, xenograft mice arising from ETS-1 over-expressing cells had more liver metastases. In the clinical specimens, ETS-1 expression was significantly higher in NSCLC cancerous tissues than adjacent nontumorous tissues and positively associated with tumor size, T stage, $\mathrm{N}$ stage and clinical stage. Patients with high levels of ETS-1 expression had significantly poorer OS (overall
\end{abstract}

$X$. Zhou and R. Zhou contributed equally to this work. 
survival) and FP (first progression) than those with low expression. Furthermore, there was a positive correlation between ETS-1 level and MVD. Conclusion: Collectively, our data reveal that ETS-1 can induce the differentiation of tumor cells into endothelial-like cells and further promote metastatic dissemination in NSCLC.

(C) 2018 The Author(s)

Published by S. Karger AG, Basel

\section{Introduction}

Solid tumors rely on angiogenesis for the generation, growth and metastasis. Antiangiogenic treatments that mainly act against the VEGF (vascular endothelial growth factor) family have been applied in different cancers [1-3], including NSCLC (non-small cell lung cancer). However, clinical trials showed only an improvement in DFS (disease-free survival) but failed to achieve a significant OS (overall survival) benefit in NSCLC [4]. Resistance to this type of therapeutic has been a prominent issue $[5,6]$. It suggests that there must be other mechanisms of angiogenesis that are VEGF-independent. Recent studies have found that tumor cells themselves can differentiate into endothelial-like cells [7-9]. These kind of tumor cells acquire the expression of endothelial markers (e.g. CD31, vWF and VE-cadherin), and are involved in the formation of vessels, allowing the cells to easily break into the circulation and travel across the body. Anti-VEGF therapy is ineffective for such cells, which may be one of the reasons why the curative effect of using it alone is not desirable enough. However, the mechanism in promoting the differentiation of tumor cells into endothelial-like cells remains unclear.

ETS-1 (E26 transformation specific-1) is an important member of the ETS transcription factors family. It regulates multiple biological and pathological processes including cell proliferation, differentiation, apoptosis, organogenesis and tissue remodeling [10-12]. Several studies have reported it as an oncogene in various human cancers [13] in which it promotes angiogenesis and degradation of extracellular matrix by activating MMPs (matrix metalloproteinases) $[14,15]$. ETS family genes are active during embryonic development, and are associated with morphogenic processes such as organ formation. Recent studies have revealed that some other members of the ETS family, such as ETV2, FLI1 and ERG could directly induce the transdifferentiation of nonvascular cells into ECs, including fibroblasts [16], amniotic cells [17] and fast skeletal muscle cells [18]. Although plenty of studies have shown that ETS-1 is particularly important for the production and maturation of the vascular endothelium, whether it participates in the conversion of nonvascular cells into endotheliallike cells hasn't been documented.

In our study, we found that ETS-1 can induce endothelial-like phenotypes and properties of NSCLC cells. Up-regulation of ETS-1 actively promoted migration and invasion in NSCLC cells both in vitro and in vivo. In clinical specimens, we confirmed that ETS-1 expression was significantly higher in tumor tissues than adjacent normal tissues and it was positively associated with MVD (microvessel density) in NSCLC tissues. In addition, the level of ETS-1 was related to tumor size, T stage, N stage and clinical stage in patients. Patients with higher ETS-1 expression had shorter OS and FP (first progression). Our findings indicate that ETS-1 may be the key factor promoting the differentiation of tumor cells into endothelial-like cells, and may further promote their metastasis, which could represent a new therapeutic strategy for NSCLC in the future.

\section{Materials and Methods}

\section{Cell lines and cell culture}

The NCSLC cell lines A549 and H460 were purchased from the Cell Bank of Chinese Academy of Sciences (Shanghai, China). The cells were cultured in RPMI-1640 medium containing 10\% fetal bovine serum at $37^{\circ} \mathrm{C}$ in the presence of $5 \% \mathrm{CO}_{2}$.

Immunofluorescence staining assay

Approximately $2 \times 10^{4}$ cells were plated into a 24 -well culture plate. After the cells attached, the medium was removed, and the cells were fixed with 4\% paraformaldehyde (Guge, Wuhan, China) for 15 min 


\section{Cellular Physiology Cell Physiol Biochem 2018;45:1827-1839 and Biochemistry Published \begin{tabular}{l|l} 
DOI: 10.1159/000487874 & $\begin{array}{l}\text { C) } 2018 \text { The Author(s). Published by S. Karger AG, Basel } \\
\text { www.karger.com/cpb }\end{array}$
\end{tabular} \\ Zhou et al.: ETS-1 Induces Endothelial-Like Differentiation in NSCLC}

at room temperature. Then, the cells were permeabilized with 0.1\% Triton-X-100 (Boster, Wuhan, China) for $20 \mathrm{~min}$ at $4^{\circ} \mathrm{C}$ and blocked with $5 \%$ BSA (Boster, Wuhan, China) for $30 \mathrm{~min}$ at room temperature. The following primary antibodies were used: anti-ETS-1 mAb (1:400, Abnova, MAB10639), anti-VE-cadherin mAb (1:400, CST, 2500S), and anti-vWF mAb (1:800, Abcam, ab6994). Incubation with primary antibodies was carried out overnight at $4^{\circ} \mathrm{C}$. After being washed in PBS, sections were incubated with CY3-conjugated goat anti-mouse/rabbit IgG antibody (1:100, Boster, Wuhan, China) for $1 \mathrm{~h}$ at room temperature. DAPI was used to label the nucleus. The slides were washed in PBS and covered with anti-fade mounting media, and the sections were photographed using a fluorescence microscope.

\section{Phagocytotic activity assay}

Direct fluorescent staining was used to detect the dual binding of Dil-ac-LDL (1, 1-dioctadecyl-3, 3,3, 3-tetramethylindocarbocyanine-labeled acetylated low-density lipoprotein) and FITC-labeled lectin. Cells were incubated with Dil-ac-LDL $(5 \mu \mathrm{g} / \mathrm{mL})$ at $37^{\circ} \mathrm{C}$ for $4 \mathrm{~h}$ and then fixed by $4 \%$ paraformaldehyde for $20 \mathrm{~min}$. Subsequently, cells were incubated with lectin $(10 \mu \mathrm{g} / \mathrm{mL})$ at $37^{\circ} \mathrm{C}$ for $1 \mathrm{~h}$. Finally, cells were photographed using a fluorescence microscope.

\section{Wound-healing assay}

A549 and H460 cells grew to $90 \%$ confluency with complete medium in a six-well culture plate. Cell monolayers were wounded by a $200 \mu \mathrm{l}$ plastic pipette tip. After washed three times to remove cell debris, cells were cultured in medium containing $2 \%$ serum at $37^{\circ} \mathrm{C}$ for $24 \mathrm{~h}$. Cells that migrated into the wound area were photographed at $100 \times$ magnifications.

Migration and invasion assays in vitro

Transwell chambers (24-well insert, $8 \mu \mathrm{m}$, Corning) were used to explore the effects of ETS-1 on the migration and invasion of both cell lines. These assays were performed as described previously [19].

Tube formation assay

For tube formation assays, $2 \times 10^{4} / 100 \mu \mathrm{l}$ cells were seeded in 96 well plates that were pre-coated with $50 \mu \mathrm{l} /$ well matrigel (BD Biosciences) and incubated at $37^{\circ} \mathrm{C}$. Approximately $4-12 \mathrm{~h}$ later, pictures were taken at $100 \times$ magnification. The capillary tubes formed were evaluated in random fields.

\section{Up-regulation and knockdown of ETS-1}

For up-regulation, ETS-1 cDNA against the human ETS-1 gene was designed and synthesized by GenePharma (Shanghai, China). ETS-1 cDNA or control were amplified by PCR and subcloned into EF1aGFP/purolentiviral plasmid vectors to generate ETS-1 and NC (negative control) cells, respectively. Lentiviruses encoded with ETS-1 cDNA or control were produced by the co-transfection of 293T cells using Lipofectamine 2000 (Invitrogen). Cells were infected with ETS-1 lentivirus or empty vector at an MOI of approximately 100 for 48 h. For knockdown, cells were transfected with 10 nM ETS-1 siRNA (5') primer GGAAUUACUCACUGAUAAA and 3' primer CCUUAAUGAGUGACUAUUU) or control siRNA (Ruibo, Guangzhou, China) using transfection reagents (Ruibo, Guangzhou, China). Cells were cultured $48 \mathrm{~h}$ after the transfection. The transfection efficiency of the control siRNA was evaluated by fluorescence microscopy. The overexpression and suppression of ETS-1 was determined by qPCR and Western blot.

\section{Western blot analysis}

Cells were homogenized by RIPA lysis buffer (Guge, Wuhan, China). After being centrifuged at $4^{\circ} \mathrm{C}$ for $20 \mathrm{~min}$, the supernatants were decanted and mixed with quadruple loading buffer. The mixture was heated for 5 minutes at $100^{\circ} \mathrm{C}$ and separated by $12 \%$ SDS-PAGE. Then, the proteins were transferred to PVDF membranes. The membranes were blocked with 5\% skim milk in TBST for $1 \mathrm{~h}$ at room temperature and then incubated overnight with primary antibodies at $4^{\circ} \mathrm{C}$. The following primary antibodies were used: anti-ETS-1 mAb (1:400, Abnova, MAB10639), anti-VE-cadherin mAb (1:400, CST, 2500S), anti-vWF mAb (1:800, Abcam, ab6994), anti-MMP-2 mAb (1:800, CST, 13132S), anti-MMP-9 mAb (1:800, CST, 13667S), anti-ICAM-1 mAb (1:1000, CST, 4915S), anti-VCAM-1 mAb (1:800, CST, 13662S) and anti- $\beta$-actin mAb (1:2000, Santa Cruz, sc-47778). The following day, membranes were washed 3 times in TBST for 5 min each and incubated with HRP-conjugated secondary antibodies at room temperature for $1 \mathrm{~h}$. After beingwashed, the membranes were imaged by ECL reagent (Guge, Wuhan, China). 


\section{Cellular Physiology Cell Physiol Biochem 2018;45:1827-1839 \begin{tabular}{cc|c|c|} 
DOI: 10.1159/000487874 & O 2018 The Author(s). Published by S. Karger AG, Basel \\
www.karger.com/cpb
\end{tabular} \\ Published online: March 05, 2018 et al.: ETS-1 Induces Endothelial-Like Differentiation in NSCLC}

RNA extraction and $q R T-P C R$

The following primer sequences were used: human ETS-1 5' primerGTGCTGACCTCAATAAGGA and 3' primer GCTGATAAAAGACTGACAGGAT; human VE-cadherin 5' primer ACAAGGACATAACACCACGAA and 3' primer TCAAACTGCCCATACTTGACT; human VWF 5' primer GCCCACCCTTTGATGAACACA and 3' primer CACTGGTCCTGCACATCGTT, and human GAPDH 5' primer AATCCCATCACCATCTTCCAG and 3' primer GAGCCCCAGCCTTCTCCAT. These assays were performed as we described previously [20].

Metastasis assay in vivo

Female BALB/c nude mice (5-week-old) were maintained under specific pathogen-free conditions at Tongji Medical College of Huazhong University of Science and Technology. For the experiment, $2 \times 10^{6}$ ETS- 1 overexpressing or empty vector transfected $\mathrm{H} 460$ cells were injected into the left lung of each mouse. After 3 weeks, the mice were sacrificed, and all the livers were removed and stained by HE (hematoxylin and eosin). This study was carried out following the guide of the National Institutes of Health for the Care and Use of Laboratory Animals.

\section{Patients and tissue specimens}

All paraffin sections along with complete clinicopathological data were obtained from 87 NSCLC patients who underwent surgical resection at Wuhan Union Hospital between September 2009 and June 2011. The 87 patients were aged from 44 to 84 years (median age 63). The use of tissues for this study has been approved by the Institute Research Medical Ethics Co-mmittee of Huazhong University of Science and Technology.

Tissue microarray (TMA) construction and immunohistochemistry assay

TMAs containing 87 NSCLC and adjacent nontumorous lung tissues were constructed. TMA sections were baked overnight at $37^{\circ} \mathrm{C}$, and then deparaffinized and rehydrated per standard protocols. Slices were boiled in sodium citrate buffer (PH 6.0) for antigen retrieval. Subsequently, sections were incubated at $4^{\circ} \mathrm{C}$ overnight with ETS-1 antibody (1:400, Abnova, MAB10639). After that, slides were incubated with a secondary antibody at room temperature for $1 \mathrm{~h}$ and then stained with DAB (3, 3-diaminobenzidine tetrahydrochloride). Finally, all sections were counterstained with hematoxylin. As the negative control, sections incubated with PBS were used. Stained cell proportions were scored as follows: $1(<20 \%$ positively stained cells); 2 (21-40\% positively stained cells); 3 (41-60\% positively stained cells); 4 (61-80\% positively stained cells); and 5 (81-100\% positively stained cells). Staining intensity was scored per the following standard: 0 (no staining); 1 (weak staining: light yellow); 2 (moderate staining: yellow brown) and 3 (strong staining: brown). The median value of IHC scores was 8; therefore low and high expression were set at scores of $<8$ and $\geq 8$, respectively.

\section{MVD analysis}

To evaluate tumor angiogenesis, MVD was determined by immunohistochemical staining of CD31 (1:100, CST, 77699S). Any more than three brown-stained ECs or EC clusters that were clearly separate from tumor cells and connective tissue elements were considered as a countable microvessel. MVD was calculated by dividing the total microvessel number by the total area.

\section{KM (Kaplan Meier) plotter database analysis}

KM-Plotter platform (http://kmplot.com/analysis/) was an online survival analysis software to assess the prognostic value of various genes in several cancers [21]. ETS-1 was entered as the gene symbol (Affy ID: 214447_at), and the analysis was performed in 1926 NSCLC patients. The median value of ETS-1 expression was used to split patients into the high and low ETS-1 groups. Univariate regression analysis was used to calculate the HR and P values.

\section{Statistical analysis}

All results shown represent the mean \pm SD from triplicate experiments. Two-tailed Student's t-test, the Kruskal-Wallis test and Kaplan-Meier survival analysis were conducted to analyze all data by SPSS 20.0 software. A significant difference was indicated as ${ }^{*} \mathrm{P}<0.05,{ }^{* *} \mathrm{P}<0.01,{ }^{* * *} \mathrm{P}<0.001$. 


\section{Cellular Physiology Cell Physiol Biochem 2018;45:1827-1839 \begin{tabular}{l|l} 
and Biochemistry Published online: March 05, 2018 & $\begin{array}{l}\text { (c) } 2018 \text { The Author(s). Published by S. Karger AG, Basel } \\
\text { www.karger.com/cpb }\end{array}$
\end{tabular}}

\section{Results}

$\mathrm{H}_{2} \mathrm{O}_{2}$ promotes differentiation of human NSCLC cells towards endothelial-like cells by upregulating ETS-1 expression

We chose $\mathrm{H}_{2} \mathrm{O}_{2}$ as an ETS-1 activator which had been previously reported [22]. Human NSCLC cell lines A549 and H460 were seeded into six-well culture plates. The following day, $\mathrm{H}_{2} \mathrm{O}_{2}$ was added and then cells were incubated $30 \mathrm{~min}$, followed by $4 \mathrm{~h}$ recovery time at $37^{\circ} \mathrm{C}$. The EC-specific marker vWF was detected by WB (Western blot) and immunofluorescence staining. As shown in Fig. 1A, vWF was activated in both cell lines and increased in a dose-dependent manner. However, EC marker CD31 was not expressed with $\mathrm{H}_{2} \mathrm{O}_{2}$ incubation. We conducted tube formation assays to evaluate whether the tube formation ability of these cells could be enhanced by $\mathrm{H}_{2} \mathrm{O}_{2}$. Consistently, the tube area of both cell lines was increased with $\mathrm{H}_{2} \mathrm{O}_{2}$ incubation (Fig. 1C). To determine whether ETS-1 mediates this differentiation, we detected expression of ETS-1 in both cell lines by WB and immunofluorescence staining. Encouragingly, after $\mathrm{H}_{2} \mathrm{O}_{2}$ administration, ETS- 1 was remarkably increased and also acted in a dose-dependent manner (Fig. 1B). In addition, immunofluorescence staining showed $\mathrm{H}_{2} \mathrm{O}_{2}$ induced ETS-1 nuclear translocation which indicated transcriptional activation of ETS-1 (Fig. 1B, lower). To further explore the role of ETS-1 in endothelial-like differentiation, we knocked down ETS-1 expression through siRNA, and then added $\mathrm{H}_{2} \mathrm{O}_{2}$ as described before. We observed that $\mathrm{vWF}$ was no longer expressed after ETS-1 silencing, even with $\mathrm{H}_{2} \mathrm{O}_{2}$ administration (Fig. 1D). These data collectively showed that $\mathrm{H}_{2} \mathrm{O}_{2}$ induced endothelial-like differentiation in NSCLC cells by up-regulating ETS-1 expression.

$\mathrm{H}_{2} \mathrm{O}_{2}$ promotes migration and invasion of human NSCLC cells in vitro

Cells' abilities of migration and invasion are basic functions required for metastatic progression of tumors. It has been reported that endothelial-like cells differentiated from tumor cells possess increased

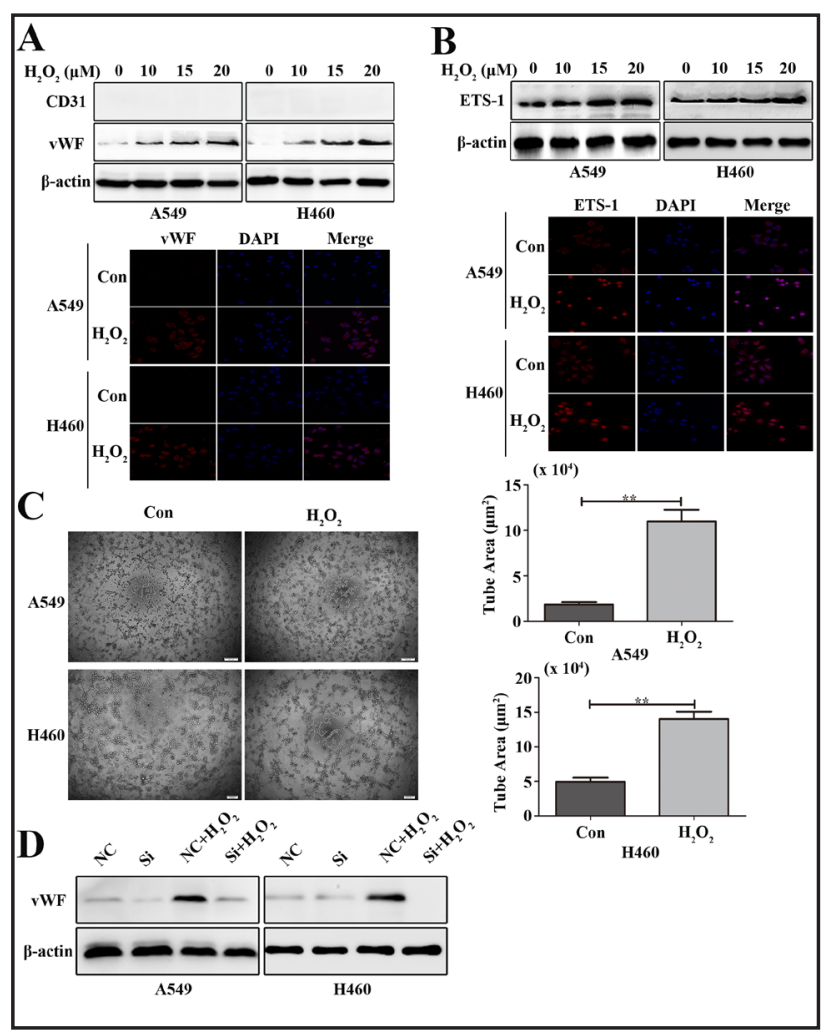

Fig. 1. $\mathrm{H}_{2} \mathrm{O}_{2}$ promotes differentiation of human NSCLC cells towards endothelial-like cells by up-regulating ETS1 expression. A-D. NSCLC cell lines A549 and H460 were incubated with $\mathrm{H}_{2} \mathrm{O}_{2}(0,10,15$ and $20 \mu \mathrm{M}$ in $\mathrm{WB} ; 15 \mu \mathrm{M}$ in immunofluorescence staining and tube formation assay) for $30 \mathrm{~min}$, followed by $4 \mathrm{~h}$ recovery time. A. Upper panel: WB results of EC-specific proteins vWF and CD31 derived from cells treated with $\mathrm{H}_{2} \mathrm{O}_{2}$. Lower panel: Immunofluorescence staining showing both cells express vWF after culture with $\mathrm{H}_{2} \mathrm{O}_{2}(200 \times)$. B. Upper panel: WB results of ETS-1 protein derived from cells treated with $\mathrm{H}_{2} \mathrm{O}_{2}$. Lower panel: Immunofluorescence staining of ETS-1 in both cell lines after culture with $\mathrm{H}_{2} \mathrm{O}_{2}(200 \times)$. C. Left panel: Images of tube formation assays of cells treated with $\mathrm{H}_{2} \mathrm{O}_{2}(100 \times)$. Right panel: Statistical results of tube area per field (analyzed by $\mathrm{t}$-test). Values represent the mean $\pm \mathrm{SEM}$ of three independent experiments. ${ }^{* *} \mathrm{P}<0.01$. D. WB results of $\mathrm{vWF}$ protein levels from cells treated with $\mathrm{H}_{2} \mathrm{O}_{2}$ alone or combined with ETS-1 silencing. Con: untreated group. NC: negative control group. Si: ETS-1 silenced group. 


\section{Cellular Physiology \begin{tabular}{ll|l} 
and Biochemistry Published online: March 05, 2018 & $\begin{array}{l}\text { C) } 2018 \text { The Author(s). Published by S. Karger AG, Basel } \\
\text { www.karger.com/cpb }\end{array}$ \\
\hline
\end{tabular}

metastatic ability than the original tumor cells. We first conducted a wound healing assay to evaluate the migration ability of these cells. The assay indicated that the addition of $\mathrm{H}_{2} \mathrm{O}_{2}$ enhanced the migration ability of both cell lines (Fig. 2A). Then, transwell assays were used to verify this finding. Not surprisingly, the transwell assays, including the migration and matrigel invasion assays, confirmed that $\mathrm{H}_{2} \mathrm{O}_{2}$ promoted the metastatic ability of the NSCLC cell lines (Fig. 2B).

\section{ETS-1 promotes differentiation of endothelial-like cells}

from human NSCLC cell line H460

To verify the role of ETS-1 in human NSCLC cell line differentiation into endothelial-like cells, we constructed ETS-1 overexpressing H460 cells, named ETS-OE. EC markers vWF and VE-cadherin were clearly present on ETS-OE cells as detected both by WB analysis, qRT-PCR analysis and immunofluorescence, whereas they were hardly present on vector control cells (Fig. 3A). However, other EC markers, CD31 and CD34 were not detected in either group by WB. We

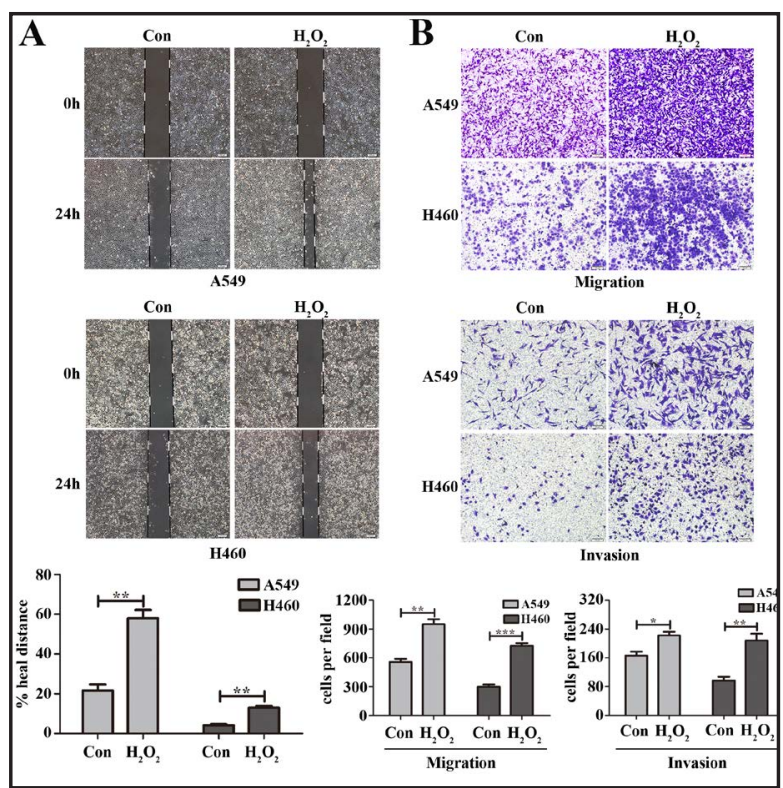

Fig. 2. $\mathrm{H}_{2} \mathrm{O}_{2}$ promotes the migration and invasion of human NSCLC cells in vitro. A-B. A549 and H460 cells were incubated with $\mathrm{H}_{2} \mathrm{O}_{2}(15 \mu \mathrm{M})$. A. Upper panel: Images of wound healing assays of cells treated with $\mathrm{H}_{2} \mathrm{O}_{2}(40 \times)$. Lower panel: Statistical results of the percentage of wound-healing distance. B. Upper panel: Images of transwell migration assays and invasion assays of cells treated with $\mathrm{H}_{2} \mathrm{O}_{2}$ $(100 \times)$. Lower panel: Statistical results of average number of cells invading through transwell membrane per field. All data were analyzed by t-test. Values represent the mean \pm SEM of three independent experiments. ${ }^{*} \mathrm{P}<0.05$, ${ }^{* *} \mathrm{P}<0.01$, $* * * \mathrm{P}<0.001$. Con: untreated group.
Fig. 3. Role of ETS-1 in endotheliallike cells derived from human NSCLC cell line H460. A. Left panel: WB results of ECspecific proteins vWF, VE-cadherin, CD31 and CD34 derived from both groups. Middle panel: qRT-PCR analysis of relative mRNA expression of vWF, VE-cadherin and ETS-1 in both groups. Right panel: Immunofluorescence staining showed H460 cells expressed vWF and VE-cadherin with ETS-1 up-regulation (200x). B. Left panel: Images of tube formation assays of both groups $(100 \times)$. Right panel: Statistical results of tube area per field. C. H460 cells took in Dil-ac-LDL (red) and lectin (green) with ETS-1 up-regulation (200×). All data were analyzed by t-test. Values represent the mean \pm SEM of three independent experiments. ${ }^{*} \mathrm{P}<0.05,{ }^{* *} \mathrm{P}<0.01$, $* * * \mathrm{P}<0.001$. Vector: empty vector group. ETS-OE: ETS-1 over-expression group.

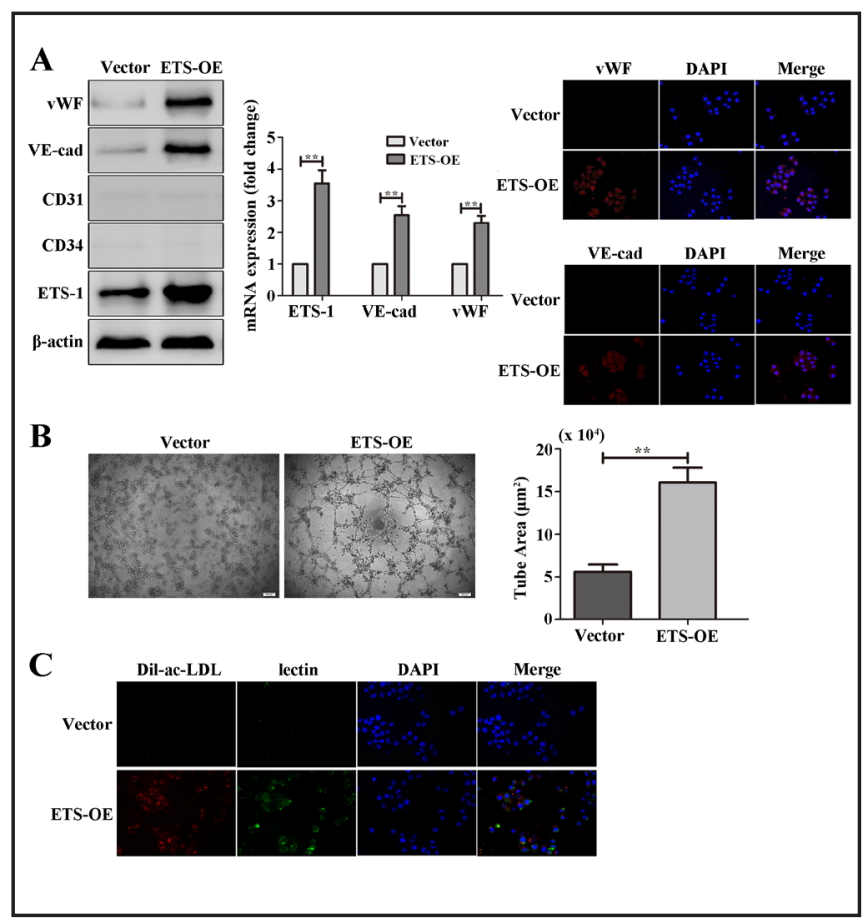


also conducted tube formation assays to evaluate whether the tube forming ability of these cells could be affected by ETS-1. As we expected, the tube area of ETS-1 overexpressing cells was much increased (Fig. 3B). ECs have the specific ability of uptaking Dil-ac-LDL, red) and binding to lectin (green). ETS-1 overexpressing cells were observed to emit both red and green signals under the laser scanning confocal microscopy (Fig. 3C). These findings indicated that ETS-1 promoted the human NSCLC cell line H460 to differentiate into endothelial-like cells.

\section{ETS-1 promotes metastasis of human NSCLC cell line H460 in vitro and in vivo}

To evaluate the role of ETS- 1 in the metastatic ability of H460 cells, we performed wound healing and transwell assays on both groups mentioned above. As shown in Fig. 4A, ETS-1 up-regulated cells showed much stronger metastatic ability than vector cells. To then confirm whether ETS-1 regulated MMP2 and MMP9 expression, we conducted WB in both groups. MMP2 and MMP9 have been used as predictive markers for NSCLC metastasis. Not surprisingly, MMP9 and MMP2 were up-regulated in ETS-1 overexpressing cells (Fig. 4B, upper). Adhesion molecules, ICAM-1 and VCAM-1, which are expressed on vascular ECs, have been reported to be responsible for the formation of strong adhesion between tumor cells and the endothelium, which further promotes metastasis. We also found VCAM-1 and ICAM1 were increased in ETS-1 overexpressing cells (Fig. 4B, lower). To verify the in vitro results showing that ETS-1 contributed to metastasis in H460 cells, in vivo mouse studies were performed. Orthotopic xenograft mouse models were generated by injecting vector $(n=4)$ and ETS-1 overexpressing cells $(n=4)$ into the lungs of BALB/c nude mice. Liver metastases were evaluated by H\&E staining 3 weeks after injection (Fig. 4C, left). The average number

Fig. 4. ETS-1 promotes metastasis of human NSCLC cell line $\mathrm{H} 460$ in vitro and in vivo. A. Upper panel: Images of wound healing assays in both groups (40×). Statistical results of percentage of wound-healing distance. Lower panel: Images of transwell migration assays and invasion assays in both groups $(100 \times)$. Statistical results of average number of cells invading through the transwell membrane per field. B. Upper panel: WB results of MMP2 and MMP9 proteins extracted from both groups. Lower panel:
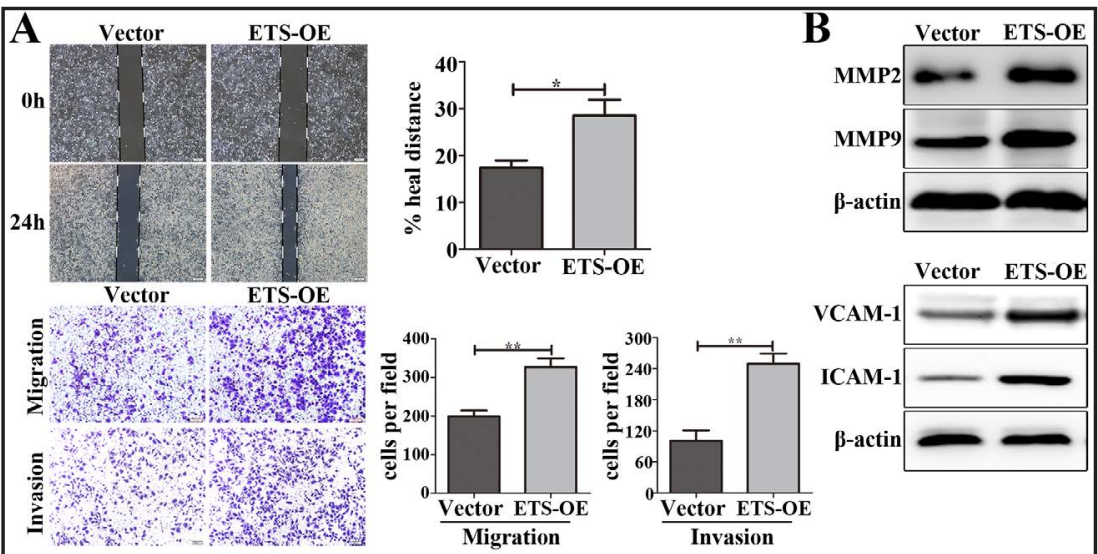

C
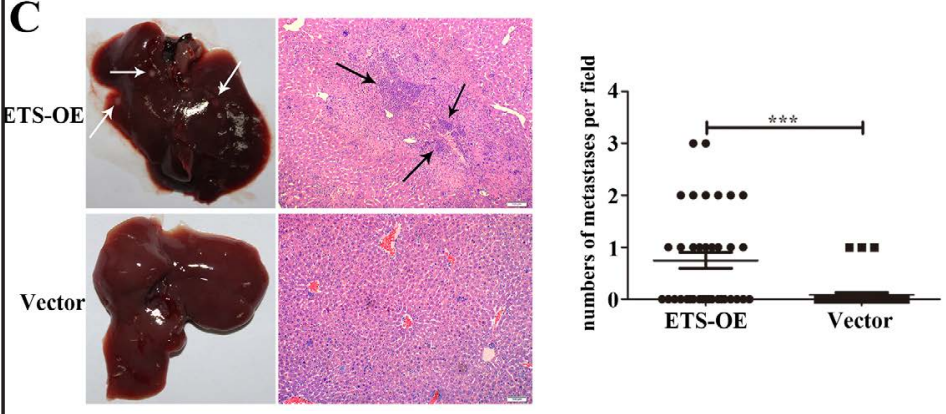

WB results of VCAM-1

and ICAM-1 proteins extracted from both groups. C. Left panel: Representative images of liver orthotopic xenograft mice from both groups (metastatic nodules pointed out by white arrows). Photographs and H \& E staining $(100 \times)$ of metastatic tumor nodules (pointed out by black arrows). Right panel: The numbers of tumor metastatic nodules in these sections were counted. All data were analyzed by t-test. Values represent the mean \pm SEM of three independent experiments. ${ }^{*} \mathrm{P}<0.05$, ${ }^{* *} \mathrm{P}<0.01,{ }^{* * *} \mathrm{P}<0.001$. Vector: empty vector group. ETS-OE: ETS-1 over-expression group. 


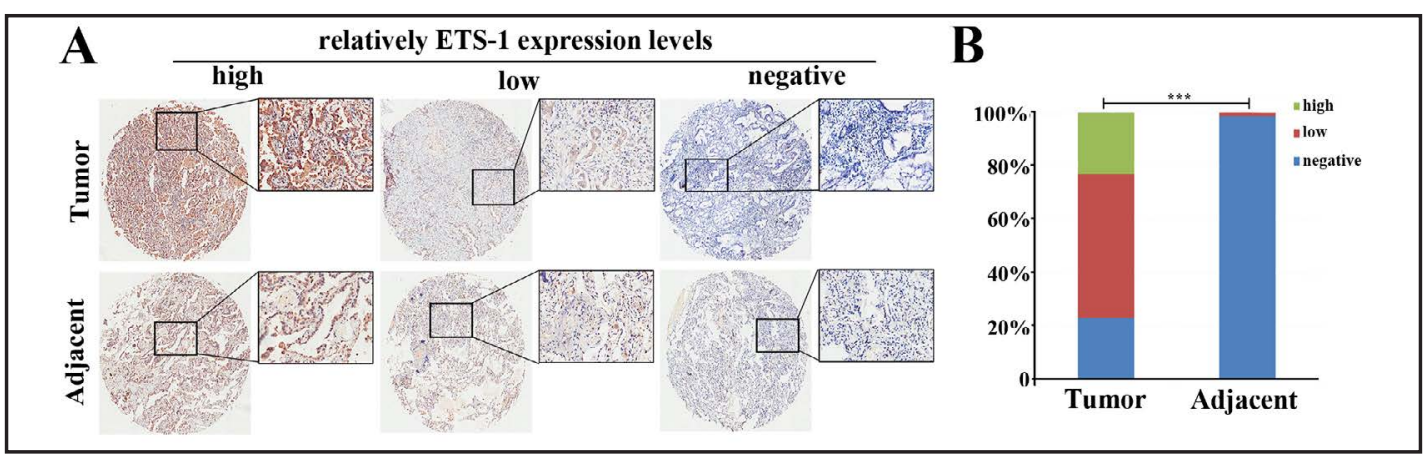

Fig. 5. ETS-1 expression in NSCLC tissues. A. Representative immunohistochemistry images of relatively high expression, low expression and negative expression in tumor tissues and adjacent nontumorous tissues (400×, partial enlarged view: 1000×). B. Percentage of cases with different staining intensity of ETS-1 in the tumor or adjacent nontumorous tissues in the 87 patients. Data were analyzed by a paired $t$-test. $* * * \mathrm{P}<0.001$.

of metastatic nodules per field was 0.75 in the ETS- 1 overexpressing group, whereas nearly no metastatic nodules (0.08) were observed in the vector group $(\mathrm{P}<$ 0.001 , Fig. $4 \mathrm{C}$, right). These results revealed that ETS-1 promoted the migration and invasion of H460 cells in vitro, and facilitated liver metastasis in the lungs of orthotopic xenograft mice.

ETS-1 is up-regulated in human NSCLC tissues, and high ETS-1 expression is positively correlated with MVD

We first detected the expression level of ETS-1 in 87 paired NSCLC tissues by immunohistochemistry. According to the results, ETS-1 was mainly presented in the cytoplasm in both tumorous tissues and adjacent nontumorous tissues (Fig. 5A). In tumor tissues, 23\% (20/87) showed high staining, $54 \%$ (47/87) showed low staining and $23 \%$ (20/87) showed negative staining. In adjacent nontumorous tissues, the corresponding results were $0 \%, 1.15 \%$ and $98.85 \%$ for high, low, and negative staining, respectively. ETS-1 expression was apparently higher in NSCLC tissues than that in the corresponding adjacent nontumorous tissues in these 87 cases $(\mathrm{P}<0.001$, Fig. 5B).

To explore the role of ETS- 1 in angiogenesis, we calculated the MVD from CD31 immunohistochemical staining. For patients with high ETS-1 expression $(n=20)$, the average MVD in tumor tissue was $74.60 / \mathrm{mm}^{2}$, while it was $66.72 / \mathrm{mm}^{2}$ for median ETS-1 expressing $(n=47)$ and $58.14 / \mathrm{mm}^{2}$ for low ETS-1 expressing $(n=20)$ patients. We evaluated
Table 1. Association between ETS-1 expression and clinicopathological parameters in NSCLC patients. ${ }^{a}$ Used t-test. ${ }^{b}$ Used chi-square test. P, positive expression; $\mathrm{N}$, negative expression

\begin{tabular}{|c|c|c|c|}
\hline \multirow[b]{2}{*}{ Variable } & \multicolumn{2}{|c|}{ ETS-1 Expression level } & \multirow{2}{*}{$\begin{array}{l}\text { P value } \\
\text { (P vs. N) }\end{array}$} \\
\hline & $\begin{array}{l}\text { Positive } \\
(\mathrm{N}=67)\end{array}$ & $\begin{array}{c}\text { Negative } \\
(\mathrm{N}=20)\end{array}$ & \\
\hline \multicolumn{4}{|l|}{ Agea (years) } \\
\hline Median & 64 & 60 & \multirow{2}{*}{0.095} \\
\hline Range & $44-84$ & $49-73$ & \\
\hline \multicolumn{4}{|l|}{ Genderb, n(\%) } \\
\hline Male & $39(58.2)$ & $8(40.0)$ & \multirow{2}{*}{0.152} \\
\hline Female & $28(41.8)$ & $12(60.0)$ & \\
\hline \multicolumn{4}{|l|}{ Tumor sizeb(cm), n(\%) } \\
\hline$<4$ & $23(34.3)$ & $16(80.0)$ & \multirow{2}{*}{$<0.001$} \\
\hline$\geq 4$ & $44(65.7)$ & $4(20.0)$ & \\
\hline \multicolumn{4}{|l|}{ Pathological type ${ }^{\mathrm{b}}, \mathrm{n}(\%)$} \\
\hline Adenocarcinoma & $47(70.1)$ & $17(85.0)$ & \multirow{2}{*}{0.186} \\
\hline Squamous carcinoma & $20(29.9)$ & $3(15.0)$ & \\
\hline \multicolumn{4}{|l|}{ T stage ${ }^{\mathrm{b}}, \mathrm{n}(\%)$} \\
\hline $1-2$ & $46(68.7)$ & $18(90.0)$ & \multirow{2}{*}{$<0.001$} \\
\hline $3-4$ & $21(31.3)$ & $2(10.0)$ & \\
\hline \multicolumn{4}{|l|}{ N stage ${ }^{b}, n(\%)$} \\
\hline $0-1$ & $45(67.2)$ & $18(90.0)$ & \multirow{2}{*}{$<0.05$} \\
\hline $2-3$ & $22(32.8)$ & $2(10.0)$ & \\
\hline \multicolumn{4}{|l|}{ Clinic stageb, n(\%) } \\
\hline I- II & 36 (53.7) & $16(80.0)$ & \multirow{2}{*}{$<0.05$} \\
\hline IIII & $31(46.3)$ & $4(20.0)$ & \\
\hline
\end{tabular}


the relationship between ETS1 expression and MVD by the Kruskal-Wallis test. As shown in Fig. 6A, tumor tissues with high expression of ETS-1 were correlated with higher MVD $(\mathrm{P}<0.001)$. These results indicated that ETS-1 was associated with tumorigenesis and promoted angiogenesis in human NSCLC.

High expression of ETS-1 is correlated with poor prognosis in NSCLC patients

We next analyzed the correlation between ETS-1 expression and clinicopathological features to reveal the clinical significance of ETS-1 in NSCLC. Significant differences were found in regard to correlations of ETS-1 expression and tumor size $(\mathrm{P}<0.001), \mathrm{T}$ stage $(\mathrm{P}<0.001)$, N stage $(\mathrm{P}<0.05)$ and clinical stage $(\mathrm{P}<0.05)$ (Table 1). There was no statistical relationship between ETS-1 expression and the other clinic pathological parameters, including age, gender and pathological patterns (Table 1). For all patients, the median survival was 33 months and the median follow-up time was 40 months. Kaplan-Meier survival analysis demonstrated that ETS-1 highexpressing patients had poor OS compared to those with low ETS- 1 expression $(\mathrm{P}<0.001$, Fig. 6A). Consistently, KM plotter database analysis showed patients with high ETS-1 levels were observed to have shorter OS (Fig. 6C) and FP (Fig. 6D) than those with high levels. Taken together, these results suggested that ETS-1 was up-regulated in NSCLC and was associated with the progression and metastasis of NSCLC. Moreover, ETS-1 high expression predicted a poor outcome in NSCLC.

\section{Discussion}

In the traditional view, tumor vascularization mainly occurs through the following two methods, sprouting angiogenesis and IMG (intussusceptive microvascular growth) [23]. During the past few years, different manners of tumor angiogenesis have been revealed, including glomeruloid angiogenesis, vasculogenic mimicry [24], looping angiogenesis and vessel co-option [5, 25]. However, we focus on a novel source of ECs, which is derived from tumor cells directly. Several initial reports have shown the generation of ECs from malignant cells in lymphomas [26], neuroblastoma [7], head and neck cancer [27] and breast cancer [28]. These kinds of cells have the following characteristics. On one hand, they have the phenotype of ECs and angiogenic abilities, so that they can easily go through vascular barriers with the endothelioid camouflage. On the other hand, they retain the characteristics 


\section{Cellular Physiology Cell Physiol Biochem 2018;45:1827-1839

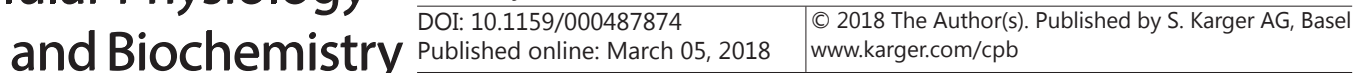

Zhou et al.: ETS-1 Induces Endothelial-Like Differentiation in NSCLC

of gene mutation and genomic instability as tumor cells $[29,30]$. These features result in a high resistance to anti-VEGF therapy, and cell differentiation in solid tumors indicates poor prognosis. Exploring the mechanisms underlying this cell differentiation is of great importance to tumor therapy.

ETS-1 promotes the generation and maturation of ECs from endothelial progenitors [31]. Our research showed that ETS-1 can also induce the endothelial differentiation of tumor cells. ETS-1 overexpressing NSCLC cells express EC markers vWF and VE-cadherin and have increased tube forming ability, as well as an increase in the ECs' specific properties to uptake Dil-ac-LDL and lectin. Also, ETS-1 expression was positively associated with MVD in NSCLC tissues, which was also reported in ovarian cancer [32]. High MVD has been reported to be independently correlated with poor DFS or OS in several cancers [33]. We suspect that a high MVD is related to an increasing number of endothelial-like cells derived from tumor cells, which is promoted by ETS-1.

Close associations between ETS-1 expression in the primary tumor and both tumor progression and lymph node metastasis have been found in gastric cancer [34]. Consistently, we found ETS-1 expression was higher in cancerous tissues than in adjacent normal tissues in clinical specimens of NSCLC patients. What's more, ETS-1 expression was positively associated with tumor size, $\mathrm{T}$ stage, $\mathrm{N}$ stage and clinical stage. Our in vivo studies also confirmed that ETS- 1 promoted liver metastasis. The pro-metastatic function of ETS- 1 in gastric cancer was associated with poor OS [34]. Consistently, in our study, patients with high levels of ETS-1 expression had shorter OS and FP. These results indicate that ETS-1 promotes tumorigenesis and progression in NSCLC, and its expression might be a useful marker for predicting lymph-node metastasis and outcomes for patients with malignancies.

In vitro, we also found that ETS-1 significantly promoted NSCLC cell migration and invasion. In the previous studies, ETS-1 was shown to be co-expressed with and induce MMPs expression in different types of carcinomas [15, 35]. MMPs play an important role in the invasion and migration of cancer cells and thus in metastasis and tumorigenesis [36]. Our results were consistent with these studies. ICAM- 1 and VCAM- 1 are CAMs (cell adhesion molecules) which are responsible for cell-cell and cell-ECM interactions. They are critical in the formation of strong adhesion between tumor cells and the endothelium [37]. Studies have shown that the positive expression of ICAM-1 was associated with depth of tumor invasion and lymph node metastasis in oral cancer [38], and that CAMs were related with distant metastasis and poor outcomes in colorectal cancer [39]. Moreover, Kong et al. found adhesion molecule expression in tumor-derived ECs in hepatocellular carcinoma [40]. Our results revealed that ETS- 1 up-regulation led to the expression of ICAM- 1 and VCAM- 1 in H460 cells, which suggests that up-regulation of adhesion molecules may be the mechanism responsible for the enhanced adhesion of tumor cells to ECs, and thus for their improved metastatic ability.

The microvascular monolayer of the endothelial barrier is the last line of defense against tumor metastasis. We speculate that appearing as ECs helps tumor cells to adhere to ECs which participate in the composition of vessels, and tumor cells can therefore move through the vascular barrier and enter the blood circulation. Meanwhile, tumor cells that appear as ECs can implant into distant organs more easily when they arrive, since they can easily traverse the endothelial barrier in these organs. Therefore, we suggest that differentiation into endothelial-like cells is an important method that tumor cells use for metastasis.

In this paper, we identified the importance of tumor cells differentiating into endotheliallike cells in NSCLC. However, there are some shortcomings of our research. We did not discover the upstream or downstream pathways involved in ETS-1 signaling. In addition, our study showed that cells only acquired a partial of endothelial phenotypes, the expression of CD31 and CD34 was still negative, which might be due to the fact that the environmental stimulation in vitro is insufficient to represent the tumor microenvironment. For example, environmental stimulation in vitro is insufficient to represent the tumor microenvironment. For example, hypoxia-inducible factor renders cells capable of surviving in hypoxia and stimulates ECs growth [41]. Additionally, there has been a therapeutic study targeted the 


\section{Cellular Physiology Cell Physiol Biochem 2018;45:1827-1839

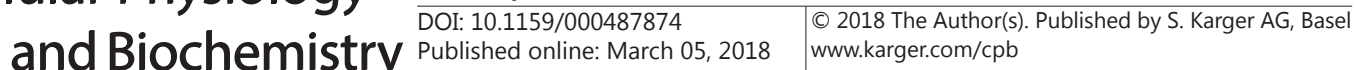

endothelial-like cells by cytotoxic hCD31 mAb in a human neuroblastoma xenograft mouse model. But this therapy led to enhanced tumor hypoxia, which in turn promotes endothelial trans-differentiation of tumor cells [30]. Combined with our research, we suspect that the endothelial-like cells may only express several endothelial phenotypes and are highly unstable. Inhibiting the key factor which results in the differentiation might be a more effective therapy. Hence, we would like to perform more extensive and in-depth studies on ETS-1 targets to fully explore its effect on angiogenesis and metastasis.

For the first time, we revealed that ETS-1 could induce lung cancer cells to differentiate into endothelial-like cells which expressed EC markers and possessed the EC properties. ETS1 was up-regulated in NSCLC tissues and might be a poor prognostic factor. Overexpression of ETS-1 induced higher metastatic potential in NSCLC cells and appeared to promote their tumorigenesis, angiogenesis, migration and invasion. Our study provides a novel mechanism and a new target for tumor angiogenesis and metastasis, which may represent a breakthrough in anti-angiogenesis and anti-metastasis therapy.

\section{Acknowledgements}

This work was supported by grants from the National Natural Science Foundation of China (No. 81302019, No. 81472201 and NO. 81672979) and the Fundamental Research Funds for the Central Universities (NO. 2016YXMS248).

We would like to thank American Journal Experts for helping us with English language editing.

\section{Disclosure Statement}

The authors declare no conflict of interest.

\section{References}

1 Hall RD, Le TM, Haggstrom DE, Gentzler RD: Angiogenesis inhibition as a therapeutic strategy in non-small cell lung cancer (NSCLC). Transl Lung Cancer Res 2015;4:515-523.

-2 Hurwitz H, Fehrenbacher L, Novotny W, Cartwright T, Hainsworth J, Heim W, Berlin J, Baron A, Griffing S, Holmgren E, Ferrara N, Fyfe G, Rogers B, Ross R, Kabbinavar F: Bevacizumab plus irinotecan, fluorouracil, and leucovorin for metastatic colorectal cancer. New Engl J Med 2004;350:2335-2342.

-3 Motzer RJ, Hutson TE, Tomczak P, Michaelson MD, Bukowski RM, Rixe O, Oudard S, Negrier S, Szczylik C, Kim ST, Chen I, Bycott PW, Baum CM, Figlin RA: Sunitinib versus interferon alfa in metastatic renal-cell carcinoma. New Engl J Med 2007;356:115-124.

-4 Raphael J, Chan K, Karim S, Kerbel R, Lam H, Santos KD, Saluja R, Verma S: Antiangiogenic Therapy in Advanced Non-small-cell Lung Cancer: A Meta-analysis of Phase III Randomized Trials. Clin Lung Cancer 2017;18:345-353 e345.

5 Vasudev NS, Reynolds AR: Anti-angiogenic therapy for cancer: current progress, unresolved questions and future directions. Angiogenesis 2014;17:471-494.

6 Miller K, Wang M, Gralow J, Dickler M, Cobleigh M, Perez EA, Shenkier T, Cella D, Davidson NE: Paclitaxel plus bevacizumab versus paclitaxel alone for metastatic breast cancer. New Engl J Med 2007;357:26662676.

7 Pezzolo A, Parodi F, Marimpietri D, Raffaghello L, Cocco C, Pistorio A, Mosconi M, Gambini C, Cilli M, Deaglio S, Malavasi F, Pistoia V: Oct-4+/Tenascin C+ neuroblastoma cells serve as progenitors of tumor-derived endothelial cells. Cell Res 2011;21:1470-1486.

8 Casal C, Torres-Collado AX, Plaza-Calonge Mdel C, Martino-Echarri E, Ramon YCS, Rojo F, Griffioen AW, Rodriguez-Manzaneque JC: ADAMTS1 contributes to the acquisition of an endothelial-like phenotype in plastic tumor cells. Cancer Res 2010;70:4676-4686. 


\section{Cellular Physiology Cell Physiol Biochem 2018;45:1827-1839 \begin{tabular}{c|c|c|} 
DOI: 10.1159/000487874 & C 2018 The Author(s). Published by S. Karger AG, Basel \\
www.karger.com/cpb
\end{tabular}

-9 Soda Y, Marumoto T, Friedmann-Morvinski D, Soda M, Liu F, Michiue H, Pastorino S, Yang M, Hoffman RM, Kesari S, Verma IM: Transdifferentiation of glioblastoma cells into vascular endothelial cells. Proc Nat Acad Sci USA 2011;108:4274-4280.

10 Maroulakou IG, Bowe DB: Expression and function of Ets transcription factors in mammalian development: a regulatory network. Oncogene 2000;19:6432-6442.

11 Kar A, Gutierrez-Hartmann A: Molecular mechanisms of ETS transcription factor-mediated tumorigenesis. Crit Rev Biochem Mol Biol 2013;48:522-543.

$\$ 12$ Findlay VJ, LaRue AC, Turner DP, Watson PM, Watson DK: Understanding the role of ETS-mediated gene regulation in complex biological processes. Adv Cancer Res 2013;119:1-61.

-13 Switzer CH, Cheng RY, Ridnour LA, Glynn SA, Ambs S, Wink DA: Ets-1 is a transcriptional mediator of oncogenic nitric oxide signaling in estrogen receptor-negative breast cancer. Breast Cancer Res 2012;14:R125.

14 Lefter LP, Dima S, Sunamura M, Furukawa T, Sato Y, Abe M, Chivu M, Popescu I, Horii A: Transcriptional silencing of ETS-1 efficiently suppresses angiogenesis of pancreatic cancer. Cancer Gene Ther 2009;16:137148.

15 Behrens P, Rothe M, Wellmann A, Krischler J, Wernert N: The Ets-1 transcription factor is up-regulated together with MMP 1 and MMP 9 in the stroma of pre-invasive breast cancer. J Pathol 2001;194:43-50.

16 Morita R, Suzuki M, Kasahara H, Shimizu N, Shichita T, Sekiya T, Kimura A, Sasaki K, Yasukawa H, Yoshimura A: ETS transcription factor ETV2 directly converts human fibroblasts into functional endothelial cells. Proc Nat Acad Sci USA 2015;112:160-165.

17 Ginsberg M, James D, Ding BS, Nolan D, Geng F, Butler JM, Schachterle W, Pulijaal VR, Mathew S, Chasen ST, Xiang J, Rosenwaks Z, Shido K, Elemento O, Rabbany SY, Rafii S: Efficient direct reprogramming of mature amniotic cells into endothelial cells by ETS factors and TGFbeta suppression. Cell 2012;151:559-575.

$>18$ Veldman MB, Zhao C, Gomez GA, Lindgren AG, Huang H, Yang H, Yao S, Martin BL, Kimelman D, Lin S: Transdifferentiation of fast skeletal muscle into functional endothelium in vivo by transcription factor Etv2. PLoS Biol 2013;11:e1001590.

19 Zhou R, Zhou X, Yin Z, Guo J, Hu T, Jiang S, Liu L, Dong X, Zhang S, Wu G: Tumor invasion and metastasis regulated by microRNA-184 and microRNA-574-5p in small-cell lung cancer. Oncotarget 2015;6:4460944622.

20 Liu JL, Gu RX, Zhou XS, Zhou FZ, Wu G: Cyclin-dependent kinase 5 regulates the proliferation, motility and invasiveness of lung cancer cells through its effects on cytoskeletal remodeling. Mol Med Rep 2015;12:3979-3985.

21 Gyorffy B, Surowiak P, Budczies J, Lanczky A: Online survival analysis software to assess the prognostic value of biomarkers using transcriptomic data in non-small-cell lung cancer. PloS one 2013;8:e82241.

22 Wilson LA, Gemin A, Espiritu R, Singh G: ets-1 is transcriptionally up-regulated by H2O2 via an antioxidant response element. FASEB J 2005;19:2085-2087.

23 Ribatti D, Crivellato E: “Sprouting angiogenesis”, a reappraisal. Developmental biology 2012;372:157-165.

24 Qiao L, Liang N, Zhang J, Xie J, Liu F, Xu D, Yu X, Tian Y: Advanced research on vasculogenic mimicry in cancer. J Cell Mol Med 2015;19:315-326.

-25 Dome B, Hendrix MJ, Paku S, Tovari J, Timar J: Alternative vascularization mechanisms in cancer: Pathology and therapeutic implications. Am J Pathol 2007;170:1-15.

-26 Streubel B, Chott A, Huber D, Exner M, Jager U, Wagner O, Schwarzinger I: Lymphoma-specific genetic aberrations in microvascular endothelial cells in B-cell lymphomas. New Engl J Med 2004;351:250-259.

-27 Chen HF, Huang CH, Liu CJ, Hung JJ, Hsu CC, Teng SC, Wu KJ: Twist1 induces endothelial differentiation of tumour cells through the Jagged1-KLF4 axis. Nature Commun 2014;5:4697.

28 D'Ippolito E, Plantamura I, Bongiovanni L, Casalini P, Baroni S, Piovan C, Orlandi R, Gualeni AV, Gloghini A, Rossini A, Cresta S, Tessari A, De Braud F, Di Leva G, Tripodo C, Iorio MV: miR-9 and miR-200 Regulate PDGFRbeta-Mediated Endothelial Differentiation of Tumor Cells in Triple-Negative Breast Cancer. Cancer Res 2016;76:5562-5572.

29 McGuire TF, Sajithlal GB, Lu J, Nicholls RD, Prochownik EV: In vivo evolution of tumor-derived endothelial cells. PloS one 2012;7:e37138.

-30 Pezzolo A, Marimpietri D, Raffaghello L, Cocco C, Pistorio A, Gambini C, Cilli M, Horenstein A, Malavasi F, Pistoia V: Failure of anti tumor-derived endothelial cell immunotherapy depends on augmentation of tumor hypoxia. Oncotarget 2014;5:10368-10381. 


\section{Cellular Physiology Cell Physiol Biochem 2018;45:1827-1839

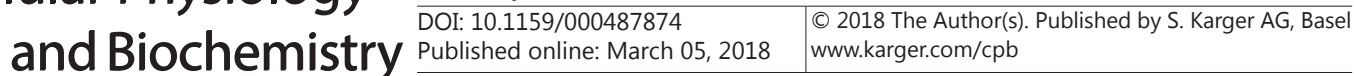

31 Craig MP, Sumanas S: ETS transcription factors in embryonic vascular development. Angiogenesis 2016;19:275-285.

-32 Lin Z, Liu Y, Sun Y, He X: Expression of Ets-1, Ang-2 and maspin in ovarian cancer and their role in tumor angiogenesis. J Exper Clin Cancer Res 2011;30:31.

-33 Dunphy F, Stack BC, Jr., Boyd JH, Dunleavy TL, Kim HJ, Dunphy CH: Microvessel density in advanced head and neck squamous cell carcinoma before and after chemotherapy. Anticancer Res 2002;22:1755-1758.

-34 Tsutsumi S, Kuwano H, Asao T, Nagashima K, Shimura T, Mochiki E: Expression of Ets-1 angiogenesisrelated protein in gastric cancer. Cancer Let 2000;160:45-50.

-35 Ghosh S, Basu M, Roy SS: ETS-1 protein regulates vascular endothelial growth factor-induced matrix metalloproteinase-9 and matrix metalloproteinase-13 expression in human ovarian carcinoma cell line SKOV-3. J Biol Chem 2012;287:15001-15015.

36 Di Nezza LA, Misajon A, Zhang J, Jobling T, Quinn MA, Ostor AG, Nie G, Lopata A, Salamonsen LA: Presence of active gelatinases in endometrial carcinoma and correlation of matrix metalloproteinase expression with increasing tumor grade and invasion. Cancer 2002;94:1466-1475.

-37 Yamada M, Yanaba K, Hasegawa M, Matsushita Y, Horikawa M, Komura K, Matsushita T, Kawasuji A, Fujita T, Takehara K, Steeber DA, Tedder TF, Sato S: Regulation of local and metastatic host-mediated anti-tumour mechanisms by L-selectin and intercellular adhesion molecule-1. Clin Exp Immunol 2006;143:216-227.

38 Usami Y, Ishida K, Sato S, Kishino M, Kiryu M, Ogawa Y, Okura M, Fukuda Y, Toyosawa S: Intercellular adhesion molecule-1 (ICAM-1) expression correlates with oral cancer progression and induces macrophage/cancer cell adhesion. Int J Cancer 2013;133:568-578.

39 Paschos KA, Canovas D, Bird NC: The role of cell adhesion molecules in the progression of colorectal cancer and the development of liver metastasis. Cellular Signal 2009;21:665-674.

40 Kong J, Kong L, Kong J, Ke S, Gao J, Ding X, Zheng L, Sun H, Sun W: After insufficient radiofrequency ablation, tumor-associated endothelial cells exhibit enhanced angiogenesis and promote invasiveness of residual hepatocellular carcinoma. J Transl Med 2012;10:230.

41 Blagosklonny MV: Hypoxia-inducible factor: Achilles' heel of antiangiogenic cancer therapy (review). Int J Oncol 2001;19:257-262. 